\title{
Developing Generic Competences in Life Sciences: the untold story of the Makerere University College of Health Sciences in Uganda
}

\author{
Lazarus Nabaho* \\ doi: http://dx.doi.org/10.18543/tjhe-4(2)-2017pp389-406
}

\begin{abstract}
Ordinarily, higher education should transform the student. Transformation refers to the development of high order subject and generic competences as a consequence of the university experience. The current discourse on generic competences, especially in the African context, focuses largely on the end (generic competences to be developed) rather than the means or process (how to develop the generic competences). Relatedly, the discussion on the subject treats generic competences as general and does not give insights into whether the priority attached to generic competences varies across disciplines. It is against this backdrop that the paper set out to identity the generic competences which are aligned with dental surgery and nursing education at Makerere University in Uganda. The paper further delved into the strategies for developing generic competences among medical students. Data for the paper was collected from dental surgery and nursing academics using interviews. The resultant data was analysed using thematic analysis. The findings revealed that problem solving, lifelong learning and interpersonal competences are aligned with life sciences. The utilitarian nature of life sciences, the rapidly changing mode of diseases and the attendant treatment options, and the highly social nature of the life sciences explicate this apparent alignment. The findings further revealed that the university employs three approaches to develop generic competences: problem-based learning, conducting generic course units, and role modelling. Therefore, it can be inferred that the generic competences to be developed on a particular academic discipline and the approaches used to develop them are a curriculum issue.
\end{abstract}

Keywords: Generic competences; higher education; life sciences; strategies; academics.

\section{Introduction}

Arguably, transformation of students from "adolescents with school-type knowledge into adults ready to enter society and the labour market at the

Lazarus Nabaho (lnabaho@umi.ac.ug),PhD in Educational Management, is a Senior Lecturer at Uganda Management Institute (Uganda). More details are available at the end of this article. 
highest level of competences available" "presupposes a fundamental purpose of higher education. ${ }^{2}$ In the quality discourse, transformation is among the dominant notions of quality in higher education and scholars such as Harvey and Knight ${ }^{3}$ regard it as the "meta-quality concept." Apologists of the transformative view of quality opine that alternative notions of quality in higher education- exceptional, value for money, consistency/perfection and fitness for purpose-are possible, though not very good, operationalisations of the transformative process rather than ends in themselves. Within the transformative perspective, quality higher education is defined and measured by the degree to which the institution has provided the student with a meaningful education experience by imparting discipline-specific knowledge as well as generic attributes and values. ${ }^{4}$

Generic competences, like other quality-related concepts, defy a single definition. Nevertheless, Barrie ${ }^{5}$ defines generic competences as "the skills, knowledge and abilities of university graduates, beyond disciplinary content knowledge, which are applicable in a range of contexts" and are acquired as a result of completing any undergraduate degree. The connotation generic suggests that the competences are necessary regardless of the field of study or the academic discipline. Generic competences are also known by a plethora of synonyms such as soft skills, key skills, common skills, essential skills, employability skills, necessary skills, transversal skills, social skills, $21^{\text {st }}$ century skills, and transferable skills. It is widely believed that generic competences are essential for both the world of work (employability) and other aspects of life and epitomise graduates as global citizens and effective members of modern day society who can act as agents of the social good. ${ }^{6}$

Globally, the notion of generic competences has gained traction in higher education and higher education institutions are currently preoccupied with developing them and demonstrating that their graduates have acquired them. The unprecedented global interest in generic competences was fuelled by the desire to bridge the gap between the world of education and the world of

${ }^{1}$ Don F. Westerheijden, Bjorn Stensaker, and Maria Joao Rosa, introduction to Quality Assurance in Higher Education. Trends in Regulation, Translation and Transformation, ed. Don F. Westerheijden, Bjorn Stensaker, and Maria Joao Rosa (Dordrecht: Springer, 2007), 7.

2 Lee Harvey and Peter Knight, Transforming higher education (Buckingham, UK: SRHE and Open University Press, 1996), 14.

${ }^{3}$ Ibid., 14.

${ }^{4}$ Tim Pitman, "Reinterpreting higher education quality in response to policies of mass education: the Australian experience," Quality in Higher Education 20, no. 3 (2014): 360.

${ }^{5}$ Simon C. Barrie, "A research-based approach to generic graduate attributes policy," Higher Education Research \& Development 23, no. 3 (2004): 262.

${ }^{6}$ Ibid. 
work. Stakeholders in higher education often hypothesise that bridging the gap between the two complementary worlds, albeit at times with different perspectives of the purpose(s) of higher education, would facilitate a smooth transition of graduates from university education to the world of work in particular and society in general.

Since the late 2011, the African Higher Education Harmonisation and Tuning Project - an initiative of the African Union in partnership with the European Union that seeks to establish an Africa Higher Education Space has been preoccupied with delineating context-specific generic competences. It should be remembered that the idea of an African higher education space was initially envisioned by the Arusha Convention of 1981. The phenomenal success of the Bologna Process in Europe, as evidenced by the creation of the European Higher Education Area, has ostensibly reignited the motivation to harmonise higher education in Africa. The African Higher Education Harmonisation and Tuning Project, through a highly consultative process, identified eighteen generic competences and these have been reported by Hahn and Teferra. ${ }^{7}$ Hahn and Teferra ${ }^{8}$ laud the Project for developing ".... an improved understanding of graduate's competences that are relevant to a variety of scopes, prominently to the labour market" and that can inform measures to close the gap between higher education and the continent's needs. The drive by universities to develop generic competences can address the incessant complaints by the employers that higher education graduates are often ill-prepared for the workplace. The perceived mismatch between the competences required by the employers and the competences of the graduates has, in part, precipitated the rampant graduate unemployment in African countries.

On a positive note, the commitment by the African Union to promote generic competences in higher education marks a radical departure from the traditional purpose of higher education of promoting "knowledge, truth and reason" to "more functional notions of the relationship between higher education and society." ${ }^{10}$ Undoubtedly, this shift in the direction of a

${ }^{7}$ Karola Hahn and Damtew Teferra, "Tuning as Instrument of Systematic Higher Education Reform and Quality Enhancement: The African Experience," Tuning Journal for Higher Education 1, no. 1(2013): 142-43, accessed May 2, 2016, http://www.tuningjournal. org/article/view/23/10.

8 Ibid., 155.

9 Ronald Barnett, Beyond All Reason: Living with Ideology in the University (Buckingham (UK: SRHE \& Open University Press, 2003), 2.

${ }^{10}$ Vanessa Brown, "How University Academics Respond to the Introduction of New Quality Assurance Policies in South African Higher Education" (PhD thesis., University of Pretoria, 2010), 69. 
utilitarian mind-set is an explicit, though belated, recognition of higher education as an instrument of socio-economic development. This recognition positions higher education as a powerful tool to enable Africa leapfrog mounting development challenges, inter alia, low economic growth, poverty and low competitiveness of the economy.

Despite the accolades above, the African Higher Education Harmonisation and Tuning initiative examines generic competences from a general perspective and does not identify competences which are aligned with particular academic disciplines. Furthermore, the Project does not delve into why certain competences should be prioritised in particular academic programmes. Finally, within the Project, there is a dearth of studies on how higher education institutions develop generic competences. It would therefore not be an overstatement to infer that the Project has placed unparalleled emphasis on what (what generic competences fit the African context and should therefore be developed?) compared to how (how best can the generic competences be developed?) or a combination of both. As a result, the discourse on generic competences has largely focused on the end (competences) rather than the means (approaches) and this resonates with extant literature. Calma, for example, posits that less attention has been paid to how students develop generic skills ${ }^{11}$ despite developing generic competences being the biggest challenge facing institutions of higher learning. ${ }^{12}$ Finally, much of the literature on generic skills is theoretical and offers policy recommendations and prescriptive advice. ${ }^{13}$

It is against this backdrop that the paper answers the following research question: What generic competences are aligned with life sciences at undergraduate level at the Makerere University College of Health Sciences and how does the College develop these competences? The paper comprises four main sections. The first section is the introduction and is followed by the methods section. Section 3.0 presents the results. The final section discusses the findings, makes propositions, and points to the direction for further research.

11 Angelito Calma, "Fixing holes where the rain gets in: Problem areas in the development of generic skills in business," Journal of International Education in Business 6, no. 1 (2013): 36.

12 Yassin Sulaiman et al., "Implementation of Generic Skills in the Curriculum" (paper presented at the EDU-COM International Conference, Perth, Australia, November 19-21, 2008).

13 Vathsala Wickramasinghe and Lasatha Perera, "Graduates', university lecturers' and employers' perceptions towards employability skills," Education + Training 52, no. 3 (2010): 227, accessed June 3, 2016, doi/full/10.1108/00400911011037355. 


\section{Methods}

Before presenting the methods, it is appropriate to sketch the context of Makerere University in general and the College of Health Sciences (CHS) in particular. Makerere University-the oldest public university in Uganda and in East Africa- was established in 1922 as a technical college. ${ }^{14}$ The University consists of ten colleges including the CHS. The CHS was established in 1924 and is the oldest medical training university unit in East Africa. Currently, the college comprises four schools: medicine, health sciences, public health, and biomedical Sciences. The next layer is the academic units or departments. Administratively, the college is headed by a principal who is assisted by a deputy principal. The dean is the administrative head of the school while departments are headed by chairs or heads of department.

The study adopted a case study design. The choice of the design was informed by two principal considerations. First, the research question necessitated a case study design. Yin ${ }^{15}$ argues that a case study is justifiable when questions of how and why are to be answered. This study answers a how question. Finally, the study aimed to "optimise understanding of the case rather than to generalise beyond it." ${ }^{16}$ This is consistent with Yin ${ }^{17}$ who postulates that "case studies are generalisable to theoretical propositions and not to populations or universes."

For a study of this nature, the respondents may include, inter alia, academics and employers. However, academics were preferred as a source of information. Two reasons explicate the declination to include employers in the study. First, the reach question - what generic competences are aligned with life sciences at undergraduate level at the Makerere University College of Health Sciences and how does the College develop these competences? - is inclined towards what is obtaining in the college and the stakeholders at the student-academic interface are therefore better placed to provide factual and reliable information. Secondly, the tracer studies by the National Council for Higher Education and the CHS have made a significant contribution by identifying generic competences for medical education from the perspective of employers.

${ }^{14}$ Makerere University, Makerere University Self-Assessment Report (Kampala: Makerere University, 2013).

15 RobertYin K, Case Study Research: Design and Methods (Thousand Oaks, CA: Sage, 2003).

${ }^{16}$ Robert E. Stake, The Art of Case Study Research (Thousand Oaks, CA: Sage, 1995), 86.

17 Yin, Case Study Research, 10. 
Purposive sampling was deemed an appropriate sampling technique for the inquiry. Merriam ${ }^{18}$ opines that "purposive sampling in based on the assumption that the investigator wants to discover, understand, and gain insight and therefore must select a sample from which the most can be learnt." The School of Health Sciences was purposively selected and the nursing and dentistry departments were also selected using the same technique. Similarly, nursing and dentistry degree programmes were selected. The aim was to have respondents from a hard-applied discipline (dental surgery) and a soft-applied discipline (nursing). Two academics who teach on each of the selected academic programmes were purposively selected to participate in the study.

The following criteria were used to select academics from each of the departments: a full-time member of staff; a minimum of three years in the university service; and having coordinated or currently coordinating a course. This brought the total number of academics from whom data was collected to four (three female and one male). The academics comprised one senior lecturer and departmental chair, two lecturers and one assistant lecturer. In terms of academic achievement, one respondent possessed a doctoral degree; three respondents possessed master's degree in clinical disciplines while one had just embarked on a master's degree. The small number of participants in the study ought to be understood against the tradition in which the research is anchored. The study is anchored in the qualitative tradition. This tradition considers the quality of respondents to be more important than the number of respondents. Similarly, the tradition regards the depth of interviews to be more important than the number of interviewees.

Data for the study was collected in July 2014 using interviews and the following data collection questions were put to the respondents: (a) what generic competences do you consider important for nursing and dental education and why? (b) how do you develop these competences in students? Each interview session lasted 45 to 60 minutes and was recorded. Consistent with the qualitative tradition, data were analysed simultaneously with data collection. Data analysis adopted Creswell's ${ }^{19}$ six steps of qualitative data analysis, namely (1) organise and prepare the data for analysis, (2) read through the data to obtain a general sense of the information and to reflect on

${ }^{18}$ Sharan Merriam B, Qualitative research and case study applications in education (San Francisco: Jossey-Bass, 1998), 61.

19 John W. Creswell, Research Design. Qualitative, Quantitative and Mixed Methods Approaches, 2nd ed. (London: Thousand Oaks: Sage Publications, 2003), 191. 
the overall meaning, (3) begin detailed analysis with a coding process, (4) use the coding process to generate a description of the categories or themes, (5) advance how the description and relationship of themes were represented in the qualitative narrative, and (6) make an interpretation or find meaning with the data. Organisation of data for analysis involved transcribing each interview. Each interview transcript was read to get a feeling for academics' wording. Second, coding was done, and two codes emerged from the data: "competences" and "strategies." Finally, themes were generated from the codes. To ensure confidentiality, the teaching department is used to identify the respondents in the report with LDD representing "Lecturer Department of Dental Dentistry Department" and LDN signifying "Lecturer Department of Nursing" followed by the order in which the interviews were conducted.

\section{Results: Generic Competences and the approach to developing them}

The findings are presented in two sections. The first section presents the generic competences which are aligned with dental surgery and nursing education while the subsequent section presents the strategies that the Makerere University College of Health Sciences uses to develop generic competences.

\section{III.1. Generic Competences for Dental Surgery and Nursing Programmes}

Nursing and dental surgery lecturers singled out three generic competences which should be integral of dental and nursing education at undergraduate level: problem-solving, lifelong learning, and interpersonal competences. These competences are examined below:

\section{III.1.1. Problem-solving}

Problem-solving was perceived to be a mandatory competence for healthcare professionals regardless of the field of specialisation. The priority that the respondents accorded to problem-solving cannot be divorced from the functional nature of dentistry and nursing. Generally, dental surgeons and nurses deploy problem-solving abilities to find answers for patients' problems. The respondents opined that life sciences are basically about solving health problems of clients and dental surgery and nursing students 
should, by implication, be prepared to solve contemporary health problems. A dental surgery lecturer attested to this imperative: "For us [health workers], life is about solving problems [related to health]...I mean our work is about solving problems" (LDD-2). Though respondents did not allude to decisionmaking as a generic competence, it can be argued that decision making is part and parcel of problem-solving. Essentially, problem-solving is a decisionmaking approach that comprises identifying the cause of a problem (diagnosis) and developing ways to remove or correct the cause. Similarly, much as critical thinking did not feature in responses of health academics, it is implied in problem-solving since it is through critical thinking that problems are normally solved.

\section{III.1.2. Lifelong learning}

Participants in the study regarded change as the only constant in the health field. This perception was based on the notion that the mode of diseases and treatment are always changing and healthcare professionals ought to keep abreast with the rapidly shifting trends in their respective fields of study. It was on the basis of this premise that the participants in the study identified lifelong learning (learning to learn) as an essential competence for students and graduates of health disciplines. Promotion of lifelong learning hinges on the idea that health practitioners are not immune from learning upon completion of their degree programmes and aims at guarding against the temptation to offer old or out-dated solutions to current problems. A nursing lecturer unequivocally illustrated this as follows:

...the mode of diseases change, the treatments change; everything changes, the way things are done changes. There are certain things I was taught when I first came here [at Makerere University] as a student nurse which have changed completely. So, if you don't continue to search for knowledge, then you can be out of practice (LND-1).

This suggests that the university experience should cultivate in students a culture of learning, unlearning and relearning so as to prevent obsolescence of knowledge and competences.

\section{III.1.3. Interpersonal attributes}

The findings on this competence suggest that dental surgeons and nurses operate in a highly social and complex environment since they unavoidably 
interface with other healthcare professionals, patients and their caregivers. The social nature of nursing and dental surgery necessitates possession of sound interpersonal abilities among the practitioners. The relevance of this competence in healthcare delivery is aptly summarised in the following dilemma that was put forward by a nursing lecturer:

If you are a nurse on the [medical] ward and you do not have [good] interpersonal skills, how will you deal with the doctor, deal with the lab attendant, how would you deal with the radiologist and then you must also deal with the dietician because your patient must eat specific foods? (LND-1).

The excerpt suggests that the needs of clients are better met through effective inter-professional collaboration and use of multi-disciplinary teams. Communication, an essential aspect of interpersonal skills, was apparent in the data. To emphasise the centrality of oral communication, a nursing lecturer said: "And when for example you are assessing a patient, there is no way you are going to talk about assessing somebody without talking about communication and people skills" (LDN-1). In as much as dental surgery lecturers were not explicit on interpersonal skills, they implicitly pointed to particular attributes when asked about how the College of Health Sciences develops generic competences. Leadership featured strongly in their responses. Coincidentally, two competences (lifelong learning and problem solving) are apparent in the Makerere University Strategic Plan (2008/2009-2017/2018):

The strategic focus for the next ten years is to produce a graduate who will not only command traditional academic and subject specific skills but will also possess generalist [sic] skills such as problem solving, reflective abilities, willingness to learn and a predisposition to lifelong learning. ${ }^{20}$

\section{III.2. Strategies for developing Generic Competences}

The College of Health Sciences at Makerere University employs a multidimensional approach to develop generic competences in students, namely using problem-based learning, offering generic or "non-core" courses, and modelling the competences by lecturers.

${ }^{20}$ Makerere University, Strategic Plan (Kampala: Makerere University, 2008). 


\section{III.2.1. Problem-Based Learning (PBL)}

The findings on this strategy point to a nexus between the perceived purpose of life sciences (solving health problems) and the approach to developing discipline-specific and generic competences (problem-based learning). Since 2003, the College of Health Sciences has been using problem-based learning (PBL), a branch of student-centred learning, to develop subject and generic competences. Problem-based learning, as the name suggests, is an approach to teaching and learning under which "topics that constitute the curriculum are converted into medical problems which students engage with to construct their own knowledge" (LDN-2). Based on a curriculum-related medical problem, teams of ten students under the guidance of the lecturer, generate learning objectives from the problem, and search for information from various sources such as internet, textbooks, and journals to achieve the objectives. Procedurally, the students present their findings on learning objectives in tutorials.

Generally, PBL is intended to "encourage learners to own their own learning" (LDD-2) and to produce self-directed learners. In other words, PBL shifts the teacher from the centre of learning and firmly places the learner at the centre of the learning process. This was illustrated by a dental surgery lecturer: “... with problem based learning...the teacher is no longer at the centre; everything [that] you do revolves around the student" (LDD-1). The role of the teacher therefore shifts from content transmission to facilitating the learning process through converting topics into medical problems, and giving guidance to learners during tutorial sessions. Therefore, it would be naïve to infer that student-centred learning diminishes the role of the lecturer. Ideally, placing the onus on students to look for the information to achieve the learning objectives or outcomes empowers students and equips them with problem solving and lifelong learning competences. The respondents alluded to these competences in the previous section. The findings demonstrate that PBL is beneficial to both the learners and the teacher in terms of the volume of information generated and development of generic competences. Concerning the volume of information, a dental surgery lecturer said: "They [students] come up with so much information and you get to learn from them yourself" (LDD-1).

On the other hand, lecturers attested to the development of generic competences among the students because of employing problem-based learning, including but not limited to problem-solving, research, teamwork, and interpersonal competences. In relation to critical thinking, a nursing lecturer said: "Problem- based learning encourages students to think outside 
the box" (LDN-2). Relatedly, asked about how the college develops generic competences, a nursing lecturer said: "the student-centred learning, the problem based learning, which we are using now,...is inculcating these virtues [or generic competences] in... students [right] from year one because we put them in groups, they select a leader who will be able to control the group as they discuss and this (leadership role) is rotational [among the 10 students] (LDN-1). Finally, a dental surgery lecturer gave a vivid narrative of how PBL contributes to the development of generic competences, that nuances our understanding of $\mathrm{PBL}$ and that encompasses a range of generic competences:

When it comes to lifelong learning, of course problem-based learning is done in tutorial style where students are given [health] problems. So, the students get an objective from that [problem] and they go out and look for the information [to achieve the objective]. So if you give a student problems and challenges and they are supposed to get answers to (sic) them, that means that even when they go for clinical work and find challenges, then you are forced if you don't know [the answer] to go and look for information. And when it comes to teamwork, they [students] are normally learning in sets of 10 for a tutorial at any one time. So, they learn from each other, they learn [how] to discuss [issues]. We have around six [degree] programmes [in the College of Health Sciences]. So, students from different programmes are learning together. I am a dental surgeon but I am learning together with someone [who] is doing [human] medicine. Even when they leave the university, they realise the importance of other professions and then that teamwork aspect comes in. So, you see the curriculum itself was built in such a way that it brings out that (sic) [generic competences] (LDD-1).

This excerpt demonstrates that generic competences can be embedded in the disciplinary curriculum and lends credence to the idea that generic competences are a curriculum issue.

The College of Health Sciences is a success story in the implementation of problem-based learning. The success of the pedagogical approach hinges on:

i. Adequate resources: adequate human and material resources must be in place if problem-based learning is to succeed because it is labourintensive. A dental surgery lecturer emphasised this aspect by asking the following question:

Problem-based learning needs lots of staff. Without staff, then how do you guide the students?...At the tutorial level, you need staff...who are committed and then you need content experts because outside the classroom environment these students should go to content experts to discuss with them what they have learnt [and] what they have read (LDD-1). 
Besides human resources, PBL requires learning resources: "It (problem-based learning) needs resources in terms of the internet, [and] text books where the students can get the information" (LDD2). Finally, the pedagogical approach requires adequate space.

ii. Committed students: a dental surgery lecturer said: "And it (problembased learning) also needs students who are committed and do not only want to receive [knowledge from the teacher] but are willing to go out and [search] for information" (LDD-1). Therefore, the success depends on, inter alia, re-orienting the mind-set of the learners from being recipients of knowledge from the teacher to constructors of their own knowledge.

iii. Support by teaching staff: this support is necessary because PBL necessitates changing the teaching approach from the traditional lecture method to student-centred learning. Despite the introduction of the instructional strategy in the college, a nursing lecturer opined that some lecturers still want to "Teach the way they were taught [at university]" (LDN-2). This statement underscores the fact that student-centred learning in general and problem-based learning in particular are bound to face resistance from academics: "I know it is not a very easy shift [from teacher-centred approach to studentcentred learning]. When they first brought it to the College [of Health Sciences], we (lecturers) resisted it. Some [lecturers] are still in denial and resisting it. Another group [of lecturers] adopted it" (LDD1). The existence of change agents explicates the successful adoption of PBL in the college: "We have had champions who have embraced change; once you have champions, the rest [of lecturers] can pick up" (LDD-2). Therefore, change agents can help the university to navigate obstacles to implementing a pedagogical reform.

Within the domain of problem-based learning, students prepare writeups which equally focus on health problems. Generally, under write-ups, students are required to observe a patient, document what has been observed, and compare what has been observed with extant literature. Through this self-discovery or constructivist approach, students are able to identify health problems and their symptoms, conditions, causes and remedies.

In conclusion, problem-based learning can be likened to hitting two birds with the same stone because it leads to the development of both subjectspecific and generic competences. However, with problem-based learning, generic competences are not taught but are a spill over from subject course 
units. This may deny students the theoretical foundation or underpinning of the competences and calls a supplementary approach to developing them such as running management course units.

\section{III.2.2. Conducting general courses}

The College runs general course units to develop generic competences. The excerpts below attest to this approach: “...our curriculum has communication skills; we have management, which includes teamwork [as a topic] and so on. So all those things (generic competences) are incorporated" (LDN-1). This approach was echoed by a dental surgery lecturer: "The College [of Health Sciences] actually put...learning items in the curriculum. When it comes to communication skills, we actually have a course unit on that" (LDD-1).

\section{III.2.3. Role modelling}

The findings on role modelling, as a strategy for developing generic competences, resurrect the desirability of exhibiting professionalism on the part of the university educator. This necessitates lecturers to teach by example and to conduct their lives in an exemplary manner. Their personal lives should be beyond reproach because they have a significant influence, either negatively or positively, on the learners in general and the development of generic competences in particular. A nursing lecturer explained:

Since this (nursing) is a people sort of profession, you must teach by example. You must be a role model. I think that is very important. So if we are talking about time keeping, you are there on time and they see you. Then the learners get accustomed that this is how things are done (LDN-1).

The excerpt demonstrates that role modelling by the teacher has an immense potential to develop generic competences in students and particularly time management and integrity.

\section{Discussion}

This study has identified generic competences which should constitute the graduate profile for dental surgery and nursing education: problemsolving, lifelong learning and interpersonal competences. These competences 
resonate with some of the 18 generic competences for African higher education that were reported by Hahn and Teferra. ${ }^{21}$

Two competences for African higher education (leadership, management and team work; and communication and interpersonal competences) have been clustered into interpersonal competence in this study. Lifelong learning appears in this study and among the 18 competences for African higher education under the African Higher Education Harmonisation and Tuning Project.

On the other hand, two competences (objective decision-making and practical cost effective problem solving; and ability for conceptual thinking, analysis and synthesis) have been nested into problem-solving. Therefore, five of the competences in the Project resonate with the competences in this study. However, there are variations between the competences from this study and some of the competences that higher education institutions in the African higher space should develop. The following competences appear in the Project Report but do not feature in this study: commitment to UBUNTU (respect for the well-being and dignity of others); ability to communicate effectively in official/national and local languages; and flexibility, adaptability and ability to respond to new situations. Other competences are: environmental and economic consciousness; ability to work in an intra and intercultural and/ or international context; ability to work independently; ability to evaluate, review and enhance quality; self-confidence; and commitment to preserve African identify and cultural heritage. There are two plausible explanations for this variation. First, the African Higher Education Harmonisation and Tuning Project is a continental initiative and respondents could have looked at the competences from continental and international perspectives. Secondly, the broad scope of Project could have given rise to the wide range of competences.

The findings suggest that a particular disciplinary field may have generic competences that are aligned with it. This partly explicates why not all the competences in the African Higher Education Harmonisation and Tuning Project were mentioned by the participants in this study. This is a pointer to the fact that while it may be desirable to promote similar generic competences across disciplines, curriculum developers and quality assurance schemes should not lose sight of peculiarities of academic disciplines. It also leads to an inference that while generic competences are general to all undergraduate programmes, each programme can have programme specific generic competences. Programme specific generic competences should be those that

${ }^{21}$ Hahn and Teferra, "Tuning as Instrument," 142-43. 
are deemed important to the disciplinary field and that the employers consider as most important when selecting graduates for entry-level jobs. This is consistent with Wickramasinghe ${ }^{22}$ who found out that there are differences in the priority given for the employability skills by employers and lecturers in the Australian context. The programme specificity should not imply that other generic competences are insignificant but that they should not be promoted in equal measure.

According to lecturers, problem-based learning has potency to develop generic competences and had indeed developed them in students. This finding corroborates Kiguli-Malwadde, Businge and Mubuuke ${ }^{23}$ who established, from the perspective of medical students, that problem-based learning was instrumental in developing the following generic competences among them: teamwork, interpersonal skills, time management, leadership skills, communication, conflict resolution, problem solving and critical thinking among students. The success of problem-based learning in developing generic competences cannot be detached from the tutorial approach that the College of Health Sciences employs. Tutorials have been found to lead to the development of generic competences. Specifically, tutorials are credited for enhancing intellectual, analytical, and communication skills, as well as creative reflection owing to their reflective nature. ${ }^{24}$

It should be noted that the College employs a dual approach to develop generic competences: embedding the competences in the curriculum and conducting standalone generic course units. The embedded approach for developing generic competences has enthusiasts and critics. The enthusiasts opine that the "embedded approaches to skills acquisition gives employability skills the same status as [subject] knowledge and obliges all lecturers to address them" while the critics of the approach - and at the same time proponents of standalone course units - argue that separate units "ensure that the skills are covered and have competent teachers to teach them." ${ }^{25}$ Despite the above contestation, the university appears to have towed a middle of the road position.

${ }^{22}$ Wickramasinghe and Perera, "Graduates', university lecturers' and employers' perceptions."

${ }^{23}$ Elsie Kiguli-Malwadde, Businge Francis, and Gonzaga Mubuuke Aloysius, "Attitudes and perceptions of students and teachers about problem based learning in the radiography curriculum at Makerere University, Uganda," European Journal of Radiography 1 (2010).

${ }^{24}$ Mwangi Ndirangu and Udoto Morris O., "Quality of learning facilities and learning environment: challenges for teaching and learning in Kenya's public universities," Quality Assurance in Higher Education 19, no. 3 (2011): 220.

${ }^{25}$ Lee Harvey, "New Realities: The Relationship between Higher Education and Employment," Tertiary Education and Management 6 (2000): 11. 
In view of the findings, the following propositions are made for Makerere University in particular and the African Higher Education Harmonisation and Tuning initiative in general. First, because generic competences are a curriculum issue, they should be embedded throughout the curriculum at undergraduate level in view of the evidence that generic competences can be learnt best if embedded in the disciplinary curriculum. ${ }^{26}$ This particular proposition has implications for curriculum development. The pedagogical approaches for dental surgery and nursing education should be informed by the generic competences which are to be developed among the learners. Similarly, curriculum designers should pay adequate attention to generic competences during the process of developing learning outcomes for discipline-specific courses. The above notwithstanding, it is prudent to emphasise a dual approach to developing generic competences. The dual approach calls for an infusion of generic competences in the disciplinary curriculum and offering generic course units. The convergence in the generic competences for dental surgery and nursing also suggests that similar generic course units for both programmes may be applicable. The second proposition is that universities should, in addition to embedding generic competences in the subject curriculum, embed the competences in student assessment. Thirdly, generic competences should be part and parcel of discipline-specific teaching and learning and academics should foster their development during the students' university experience. Furthermore, generic competences should be elevated to a quality assurance issue in higher education. This necessitates that the accreditation schemes, at national, regional and continental level, make it mandatory for universities to, inter alia, develop robust quality assurance mechanisms to ensure that generic competences are taught, assessed and reported. Finally, universities should shift from mapping out the generic competences to demonstrating greater evidence of the attainment of the competences.

A noteworthy limitation of this study, the ontological orientation in which it is anchored notwithstanding, is the small sample. Despite the limitation above, the overly interpretivist study contributes to the discourse on developing generic competences in higher education in two ways. First, the study extends scholarship on generic competences from what competences should be developed to how the competences should be developed. The approaches to developing generic competences that are employed in health sciences at Makerere University can be transferred to other disciplines in

${ }^{26}$ Clair Hughes and Simon Barrie, "Influences on the assessment of graduate attributes in higher education," Assessment \& Evaluation in Higher Education 35, no. 3 (2010), accessed June 7, 2016, doi/abs/10.1080/02602930903221485. 
general and applied fields which involve solving problems such as engineering in particular. Secondly, the study identified the preconditions for the success of student-centred learning and particularly problem-based learning. The lessons from this case study can be transferred to other higher education institutions with a view to maximising student learning.

The study nuances our understanding of how generic competences can be developed through the curriculum at undergraduate level. Arguably, the discourse on the development of generic competences is incomplete without insights on how to assess them. It is therefore recommended that future studies should investigate how universities assess generic competences. This is consistent with Calma ${ }^{27}$ who argues, "If universities are determined to develop generic skills, specific assessments must be designed to evaluate them". Finally, it is also recommended that the study is replicated in another public university that offers similar academic programmes in order to ascertain whether there are variations in the priority attached to particular generic competences across academic institutions.

\section{Bibliography}

Barnett, Ronald. Beyond All Reason: Living with Ideology in the University. Buckingham, UK: SRHE \& Open University Press, 2003.

Barrie, Simon C. "A research-based approach to generic graduate attributes policy." Higher Education Research \& Development 23, no. 3 (2004): 261-275.

Brown, Vanessa, "How University Academics Respond to the Introduction of New Quality Assurance Policies in South African Higher Education.” PhD thesis, University of Pretoria, 2010.

Calma, Agenlito. "Fixing holes where the rain gets in: Problem areas in the development of generic skills in business." Journal of International Education in Business 6, no. 1 (2013): 35-50.

Creswell, John W. Research Design. Qualitative, Quantitative and Mixed Methods Approaches. 2nd ed. London, Thousand Oaks: Sage Publications, 2003.

Hahn, Karola, and Damtew Teferra. "Tuning as Instrument of Systematic Higher Education Reform and Quality Enhancement: The African Experience." Tuning Journal for Higher Education 1, no. 1 (2013): 127-63.

Harvey, Lee, and Peter Knight. Transforming higher education. Buckingham, UK: SRHE and Open University Press, 1996.

Harvey, Lee. "New Realities: The Relationship between Higher Education and Employment." Tertiary Education and Management 6 (2000): 3-17.

${ }^{27}$ Calma, "Fixing holes where the rain gets in," 46. 
Hughes, Clair, and Simon Barrie. "Influences on the assessment of graduate attributes in higher education." Assessment \& Evaluation in Higher Education 35, no. 3 (2010): 325-334.

Makerere University. Strategic Plan. Kampala: Makerere University, 2008.

. Makerere University Self-Assessment Report. Kampala: Makerere University, 2013.

Kiguli-Malwadde, Elsie, Businge Francis, and Mubuuke Aloysius Gonzaga. "Attitudes and perceptions of students and teachers about problem based learning in the radiography curriculum at Makerere University, Uganda.” European Journal of Radiography 1, no. 4 (2009): 156-162.

Merriam, Sharan B. Qualitative research and case study applications in education. San Francisco: Jossey-Bass, 1998.

Ndirangu, Mwangi, and Maurice O. Udoto. "Quality of learning facilities and learning environment: Challenges for teaching and learning in Kenya's public universities." Quality Assurance in Higher Education 19, no. 3 (2011): 208-223.

Pitman, Tim. "Reinterpreting higher education quality in response to policies of mass education: the Australian experience." Quality in Higher Education 20, no. 3 (2014): 348-65.

Stake, Robert E. The Art of Case Study Research. Thousand Oaks, CA: Sage, 1995.

Westerheijden, Don F., Bjorn Stensaker, and Maria Joao Rosa. Introduction to Quality Assurance in Higher Education. Trends in Regulation, Translation and Transformation, edited by Don F. Westerheijden, Bjorn Stensaker, and Maria Joao Rosa, 1-11. Dordrecht: Springer, 2007.

Wickramasinghe, Vathsala, and Perera, Lasatha. 'Graduates', university lecturers' and employers' perceptions towards employability skills." Education + Training 52, no. 3 (2010): 226-244.

Yassin, Sulaiman. Hassan, Fauziah Abu., Amin, Wan, and Amiruddin, Nur. "Implementation of Generic Skills in the Curriculum." Paper presented at the EDU-COM International Conference, Perth, Australia, November 19-21, 2008.

Yin, Robert K. Case Study Research: Design and Methods. Thousand Oaks, CA: Sage, 2003.

\section{About the author}

LAZARUS NABAHO (Inabaho@umi.ac.ug) is a Senior Lecturer at Uganda Management Institute, Uganda. He holds a PhD in Educational Management of Makerere University, Uganda. Nabaho has a track record of publishing articles, book chapters and preparing policy briefs. His research areas include quality management in higher education, teaching and learning, education policy, education reforms, performance management, governance in higher education, and decentralisation and local governance. 


\title{
Developing Generic Competences in Life Sciences: the untold story of the Makerere University College of Health Sciences in Uganda
}

\author{
Lazarus Nabaho
}

\section{Copyright}

Copyright for this article is retained by the Publisher. It is an Open Access material that is free for download, distribution, and or reuse in any medium only for non-commercial purposes; provided any applicable legislation is respected, the original work is properly cited, and any changes to the original are clearly indicated. 